\title{
UV Absorptance of Titanium Dioxide Thin Films by Plasma Enhanced Deposition from Mixtures of Oxygen and Titanium- Tetrakis-Isopropoxide
}

\author{
Journal Article \\ Author(s): \\ Sonnenfeld, Axel; Rudolf von Rohr, Philipp; Hauert, Roland \\ Publication date: \\ 2006-06 \\ Permanent link: \\ https://doi.org/10.3929/ethz-b-000000776
}

Rights / license:

In Copyright - Non-Commercial Use Permitted

Originally published in:

Plasma chemistry and plasma processing 26(3), https://doi.org/10.1007/s11090-006-9022-6 


\title{
UV Absorptance of Titanium Dioxide Thin Films by Plasma Enhanced Deposition from Mixtures of Oxygen and Titanium-Tetrakis-Isopropoxide
}

\author{
Axel Sonnenfeld • Roland Hauert • \\ Philipp Rudolf von Rohr
}

Received: 27 October 2005 / Accepted: 2 February 2006 /

Published online: 7 April 2006

(C) Springer Science+Business Media, Inc. 2006

\begin{abstract}
A low pressure radio frequency discharge was used to deposit films by mixtures of oxygen and titanium (IV) isopropoxide (TTIP) at powers of $200 \mathrm{~W}$ on films of polyethylene-terephthalat and samples of quartz glass. In the non-thermal plasma, films of rather pure $\mathrm{TiO}_{2}$ could be deposited as revealed by X-ray photo-electron spectroscopy. Besides the film growth rate and the chemical composition, the spectral behaviour of the spectral transmittance of visually transparent films was determined in the range from 200 to $500 \mathrm{~nm}$. Furthermore, the absorptance of films has been derived at characteristic spectral positions of the transmission spectra of the films. Accordingly, cut-off wavelength was found to increase with deposition time from 5 to $10 \mathrm{~min}$ as well as with the concentration of TTIP in a range below $1.7 \%$. At $310 \mathrm{~nm}$, the spectral absorption coefficient (extinction coefficient $\times$ concentration) was $12 \mu \mathrm{m}^{-1}$. While keeping other parameters constant, this coefficient decreased by $4 \mu \mathrm{m}^{-1}$ due to an increase of the concentration of TTIP from $1.7 \%$ to $8 \%$. Simultaneously, the surface roughness increased as revealed by profilometry. Thus, since the chemical structure of films was found to change only marginally, a decrease of the film density is likely to cause the observed dependence of the absorption coefficient with increasing precursor concentration.
\end{abstract}

Keywords Titanium dioxide - Plasma enhanced chemical vapour deposition (PECVD) . Polymeric substrate $\cdot$ UV absorption $\cdot$ XPS

\section{Introduction}

Titanium dioxide $\left(\mathrm{TiO}_{2}\right)$ films have versatile applications, which include ultra-thin film high$\mathrm{k}$ insulators [1] $(40<\varepsilon<86)$ in integrated circuits [1-4], and surface passivation [5] as well as biocompatible coatings [6] availing their chemical and thermal resistance [7, 8].

A. Sonnenfeld · P. Rudolf von Rohr $(\varangle)$

Institute of Process Engineering, ETH Zurich, CH-8092 Zurich, Switzerland

E-mail: vonrohr@ipe.mavt.ethz.ch

R. Hauert

Empa, Materials Science and Technology, Überlandstrasse 129, CH-8600 Dübendorf, Switzerland 
Furthermore, the high refractive index material is commonly used for antireflection coatings on glass $[9,10]$, and has been proposed as photoanode layer of dye-sensitized nanocrystalline solar cells $[11,12]$. As well as this type of solar cell, light induced splitting of water by means of $\mathrm{TiO}_{2}$ [13-15] also takes advantage of its photocatalytic surface property.

Since the late eighties, numerous investigations have been dedicated to the photocatalytic activity of $\mathrm{TiO}_{2}$ films [16-23]. As a consequence, light induced hydrophilic surfaces have been found to be a striking photocatalytic phenomenon [21, 22] being of interest for new printing techniques [23].

It should yet be noted that the excellent material properties mentioned above are reported to be intrinsically tied to at least poly-crystalline $\mathrm{TiO}_{2}$ [1, 9, 21-25]. By far most common are the two tetragonal structures of $\mathrm{TiO}_{2}$, anatase and rutile. Orthorhombic brookite has been observed in dip-coated material, only [10].

High quality poly-crystalline $\mathrm{TiO}_{2}$ films are easily formed using various vapour deposition techniques $[9,26]$. Among these, chemical vapour deposition (CVD) is considered to offer the advantage of comparably low film growth temperatures. However, anatase and rutile are formed at 623 and $1073 \mathrm{~K}$, respectively [27], making substrate heating or postdeposition annealing necessary, and thereby inhibiting the application of poly-crystalline $\mathrm{TiO}_{2}$ to temperature sensitive substrate materials as for instance polymers.

Only over recent years, $\mathrm{TiO}_{2}$ films grown at temperatures below $393 \mathrm{~K}$ have come to the focus [28-37]. For instance, a purely chemical approach has been taken to deposit polycrystalline films on polymers [36]. However, the film growth rates reported are very much inferior to CVD techniques.

For amorphous $\mathrm{TiO}_{2}$ grown at low temperatures, plasma-enhanced chemical vapour deposition (PECVD) has been the dominating method, since the non-thermal plasma environment permits film growth even at room temperature [31]. But still, reports on the plasma-assisted deposition of amorphous $\mathrm{TiO}_{2}$ films on temperature sensitive materials, especially, on polymers are missing.

In order to fill this lack, we report first results on studying the deposition of amorphous $\mathrm{TiO}_{2}$ by means of PECVD on films of polyethylene-terephthalate (PET) as an example for plastic substrates. Films were deposited for varying concentrations of the deposition precursor titanium (IV) isopropoxide (TTIP) in mixtures with oxygen in a radio frequency discharge. In order to ascertain the chemical composition of films obtained, X-ray photoelectron spectroscopy has been applied.

Several polymers, e.g. polycarbonate, polyacrylic (polymethyl-methacrylate), provide excellent optical transmission in the visible range, and thus are convenient materials for substituting glass $[10,38]$. However, these materials absorb very effectively ultraviolet (UV) light causing chain degradation, accompanied by loss of flexibility and translucence [39-41]. Therefore, the absorption properties of films deposited are studied in the present work.

\section{Experimental}

\subsection{Experimental set-up and procedure}

Films were deposited in the set-up schematically shown in Fig. 1. Unless described differently later on, all parts of the set-up were made of stainless steel. The heart of the set-up is a double-walled chamber built on the basis of a T-piece pipe fitting for clamping flange (DN 250 ISO-K). Its side-flange is shut by a double-walled blanking flange, which acts as porthole. The bottom blanking flange supports the feedthroughs of the annular gas shower and the powered 


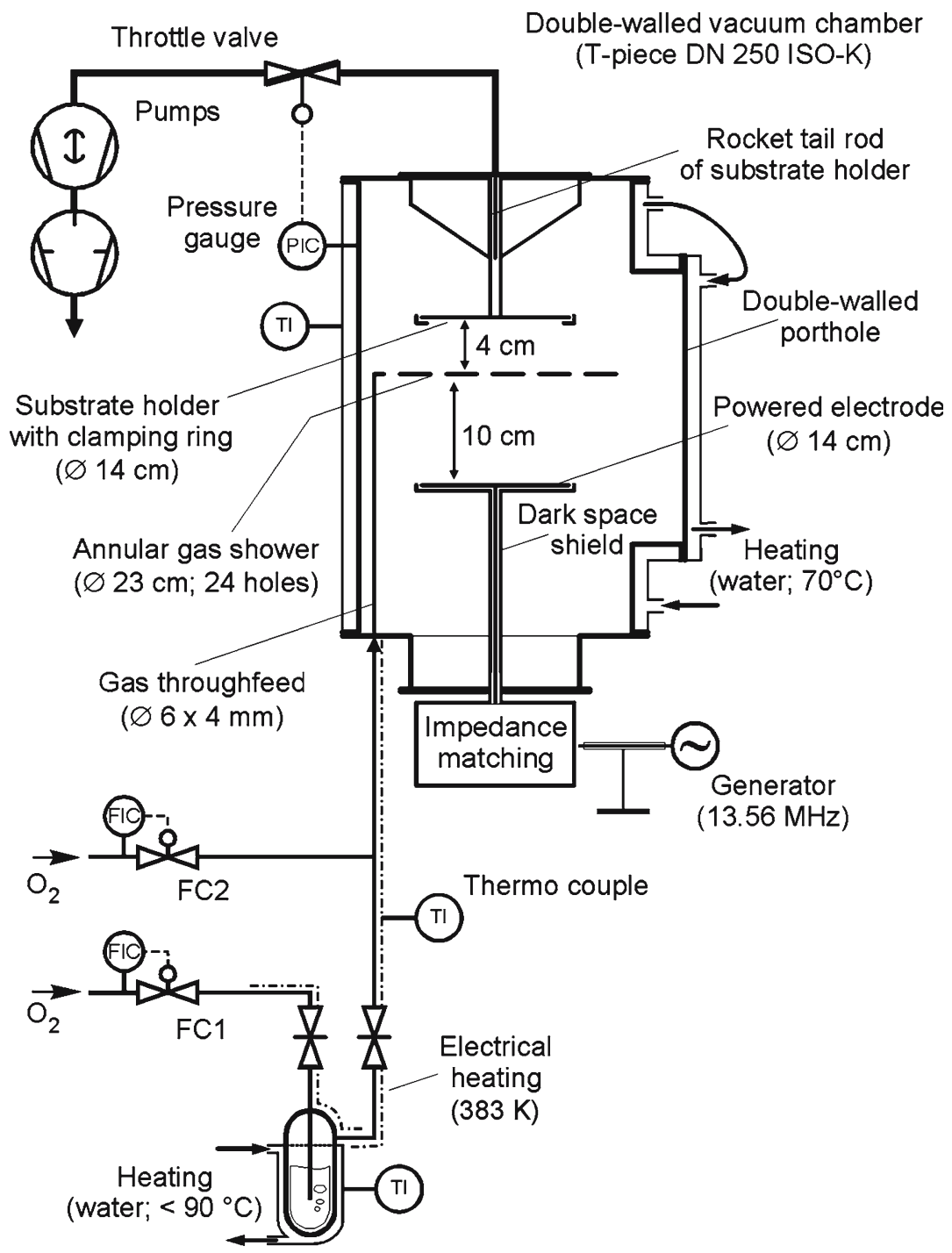

Bubbler with TTIP

Fig. 1 Scheme of the experimental set-up

electrode. Inside the chamber, at a height of $13 \mathrm{~cm}$ from the chamber bottom, the cylindrical electric feedthrough meets the electrode, which is a circular plate with a diameter of $14 \mathrm{~cm}$. Fitted into the dark space shield; gaskets of polytetrafluorethylene (PTFE) with fluoroelastomer (FPM) o-rings seal and centre the electric feedthrough and thus the electrode. The dark space gap obtained is $0.3 \mathrm{~mm}$ inhibiting parasitic discharges. The shield is grounded by thread-connection to the bottom flange. Outside the chamber, the electric feedthrough of the powered electrode is directly plugged to the output socket of a LC-matching network (DRESLER, VM 1500). The matching adapts the load impedance of the discharge configuration to the output impedance of the electric generator (DRESSLER, Cesar 1312), which supplies sinusoidal voltages of a frequency of $13.56 \mathrm{MHz}$. 
The gas throughfeed supports the annular gas shower, which has a diameter of $23 \mathrm{~cm}$. Both are made of $\varnothing 6 \times 4 \mathrm{~mm}$ tube. By means of 24 holes $(\varnothing 0.6 \mathrm{~mm})$ in the shower, the gas is dispersed toward the centre of the reactor and the substrate holder. In this study, the vertical position of the gas shower has been fixed to a distance of $4 \mathrm{~cm}$ to the substrate holder.

The substrate holder is grounded and of the same diameter as the powered electrode. It is supported by a rod with rocket tail-shaped plates fixed to the top flange of the chamber. By this means, the substrate holder is centre-positioned right beneath the exhaust gas exit.

A system of a double stage rotary pump (LEYBOLD, Trivac D 65 B) and a roots pump (LEYBOLD, RUVAC WS 1001) maintains low-pressure. The base pressure is less than $0.1 \mathrm{~Pa}$ in the chamber. The pressure is measured by a capacitance diaphragm gauge (MKS, Baratron 626A). It is connected to a MKS-651C which controls a butterfly exhaust throttle valve (MKS, 653B, DN 100 ISO-F). Thus, the pressure could be adjusted independently of the gas flux. The gas flux delivered by FC1 (MKS, $1179 \mathrm{~B}, Q_{\max }=10 \mathrm{sccm}$ ) is admixed to the flux of FC2 $\left(Q_{\max }=100 \mathrm{sccm}\right)$ after passing through the bubbler with the liquid precursor TTIP.

During experiments, a partition of the TTIP (Ti- $\left(\mathrm{O}-\mathrm{CH}_{2}\left(\mathrm{CH}_{3}\right)_{2}\right)_{4}$, CAS: 546-68-9) is diluted in the through-streaming gas according to the dependence of its vapour pressure on temperature. Therefore, the precursor temperature $T_{\text {TTIP }}$ has been controlled by means of a thermostat pumping water through the double-mantle of the bubbler. Since reference specifications concerning the vapour pressure of TTIP are fragmentary and sometimes contradictory [42-44], we estimated the concentration $c_{\text {TTIP }}$ in measuring the diminution of its volume $\Delta V_{\text {TTIP }}$ over time $\Delta t$ at fixed $T_{\text {TTIP }}$

$$
\left.c_{\mathrm{TTIP}}=\frac{[\mathrm{TTIP}]}{[\mathrm{TTIP}]+Q_{\mathrm{tot}}} \text { with [TTIP }\right]=\frac{\sigma_{\mathrm{TTIP}}}{M_{\mathrm{TTIP}}} \frac{\Delta V_{\mathrm{TTIP}}}{\Delta t} .
$$

Here, $Q_{\text {tot }}$ is the total flux of the diluting gas, i.e. oxygen, $M_{\mathrm{TTIP}}=284.25 \mathrm{~g} / \mathrm{mol}$ is the molar mass of TTIP, and $\sigma_{\text {TTIP }}=0.96 \mathrm{~g} / \mathrm{cm}^{3}$ its mass density. Hence, the resulting calibration function depending on $Q_{\mathrm{tot}}$ and $T_{\mathrm{TTIP}}$ is the basis for the values of the precursor concentration of TTIP given later on. Exemplarily, the resulting dependence for $Q_{\text {tot }}=50 \mathrm{sccm}$ is given in Fig. 2.

The monomer used was purchased from SIGMA-ALDRICH with a purity of $97 \%$. In order to further purify the monomer, it was vacuum distilled for approximately $30 \mathrm{~min}$ after fill-

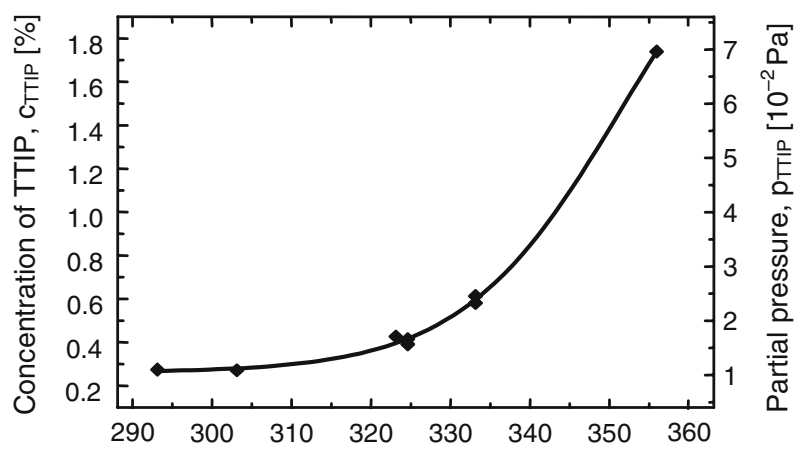

Temperature of the bubbler, $\mathrm{T}_{\text {TTIP }}[\mathrm{K}]$

Fig. 2 Calibration function for the concentration of TTIP in dependence on the bubbler temperature for $Q_{\text {tot }}=50 \mathrm{sccm}$ (left ordinate). Dependence derived from the measured volume diminution of TTIP in the bubbler over time on the basis of (1). Estimation of the partial pressure of TTIP in the vacuum chamber at a working pressure of $p=4 \mathrm{~Pa}$ (right ordinate) 
ing the bubbler. For this, the bubbler was heated to $368 \mathrm{~K}$ and pumped by maintaining base pressure in the reactor. The TTIP conditioned in such a manner served for several consecutive experiments, while keeping the monomer temperature at $T_{\mathrm{TTIP}}=333 \mathrm{~K}$ in-between the experiments.

All experiments described were conducted with an initial gas mixture of oxygen and TTIP. Variation of $c_{\mathrm{TTIP}}=0.4 \%$ to $8 \%$ was obtained by varying $T_{\mathrm{TTIP}}=333-358 \mathrm{~K}$ at constant flux $Q_{\text {tot }}=50 \mathrm{sccm}$, and at constant value of $T_{\text {TTIP }}=353 \mathrm{~K}$ by varying $Q_{\text {tot }}=10-50 \mathrm{sccm}$. In order to prevent condensation of TTIP, the inner surface of the vacuum chamber was heated to $343 \mathrm{~K}$ by pumping water of a second thermostat through the double-walled mantle of the chamber. The gas supply tubing carrying TTIP, was heated electrically to a temperature of $383 \mathrm{~K}$.

During experiments the pressure has been kept constant at $p=4 \mathrm{~Pa}$. Compared to the base pressure of less than $0.1 \mathrm{~Pa}$, it would contribute to approximately $3 \%$ of residual gas in the gas mixture. But, purging with the process gas at a pumping speed of several hundred cubic metres per hour reduces the residual gas to negligible amounts within seconds. Preliminary flow tests of different $\mathrm{O}_{2}$ /TTIP mixtures did not result in any detectable deposition, assuring that no TTIP condensates in the set-up, which might have unwontedly affected the results of the PECVD process.

Experiments were conducted at a constant forwarded power of $P_{\mathrm{f}}=200 \mathrm{~W}$. The reflected power was adjusted to $P_{\mathrm{r}}=25 \mathrm{~W} \pm 3 \mathrm{~W}$. By this means, an asymmetric RF discharge was operated between powered electrode and the grounded substrate holder and the vacuum chamber. The self bias voltage varied between 300 and $600 \mathrm{~V}$ from experiment to experiment. During a single experiment, however, it slightly increased by approximately $50 \mathrm{~V}$. Films were deposited on PET films with a thickness of $12 \mu \mathrm{m}$. The PET films were attached to the substrate holder by a special clamping ring put to the edge of the substrate holder, see Fig. 1. Since in this orientation, substrates have been coated up side down, powder agglomeration on the substrate surfaces could be reduced. Thereby, the range of the precursor concentration investigated could be extended beyond $4 \%$, where powder formation was found to develop.

PET films covering the entire substrate holder $(\varnothing 14 \mathrm{~cm})$ were used as substrate for investigations of the light absorptance of films deposited. In addition, polished quartz glass samples have been fixed onto the surfaces of the PET films in order to study film absorptance below the cut-off wavelength of PET $(\sim 310 \mathrm{~nm})$. For XPS and ellipsometric measurements pieces of $\mathrm{Si}(100)$ wafers have also been attached to the PET films.

\subsection{X-ray photoelectron spectroscopy}

To determine the concentration and the chemical status of titanium, oxygen and carbon in the films deposited on Si wafers $(1 \times 1 \mathrm{~cm})$, spectra were acquired on a Physical Electronics (PHI) Quantum 2000 spectrometer at a base pressure of less than $5 \times 10^{-7} \mathrm{~Pa}$. The samples were exposed to a monochromatized X-ray beam $\left(\mathrm{Al}-\mathrm{K}_{\alpha}: 1486.6 \mathrm{eV}\right)$. Low-energy electrons and argon ions were used simultaneously to compensate for electrical charging of insulating surface areas during analysis. Emitted photoelectrons were analyzed with a hemispherical electron energy analyzer equipped with a channel plate and a position sensitive detector. The electron take-off angle was $45^{\circ}$. The analyzer was operated at constant pass energy of $58.7 \mathrm{eV}$ giving an energy resolution of $1.05 \mathrm{eV}$. The binding energy scale was calibrated for $\mathrm{Au} 4 \mathrm{f}$ electrons to be at $84.0 \pm 0.1 \mathrm{eV}$. Elemental concentrations are given in atomic percent using the photoelectron peak areas after Shirley background subtraction (Multi-Pack, Version 6.1, Physical Electronics) and the built-in PHI sensitivity factors for calculation. To remove adventitious carbon as well as surface oxide layer, prior to analysis the sample surfaces 
were cleaned by $4 \mathrm{kV}$ argon ion bombardment for $30 \mathrm{~s}$. This accounts for a sputtering depth of $10.6 \mathrm{~nm}$. Due to residual charging during analysis, the actual peak positions had to be referenced to the Ar $2 \mathrm{p}$ peak at $241.9 \mathrm{eV}$.

\subsection{Ellipsometry and profilometry}

A variable angle spectroscopic ellipsometer (J.A. WoolLAM INC., M-2000F) was used to measure the thickness of films deposited on Si wafer samples. Two measurements were performed at three different incident angles $\left(65^{\circ}, 70^{\circ}, 75^{\circ}\right)$ in the range of 245 to $995 \mathrm{~nm}$. Best fit of the measured spectral dependencies has been found by adapting the spectral dependencies of the refractive index and the extinction coefficient of the deposited films.

Film thicknesses obtained by means of ellipsometry could be validated by masking a portion of $\mathrm{Si}(100)$ substrates during deposition, and then measuring the resulting step by stylus profilometry (TENCOR P10). The absolute deviation between the thicknesses obtained by the techniques was determined to be smaller than $15 \mathrm{~nm}$.

\subsection{UV-visible spectroscopy}

Spectral transmittance and absorptance, respectively, of the films deposited on PET and quartz was determined by a double-beam spectrometer (PERKIN-ELMER, Lambda 35) operative in the ultraviolet and visible range. Deposited films were investigated at a beam cross-section of $2 \mathrm{~mm} \times 7.5 \mathrm{~mm}$ in the focal length of the sample compartment in transmission mode. For this, a single sample $(1.5 \mathrm{~cm} \times 3.5 \mathrm{~cm} \times 12 \mu \mathrm{m})$ has been cut out of each PET film coated. Spectra were acquired from 200 to $500 \mathrm{~nm}$ and compared to the spectral absorption of uncoated PET.

Since PET exerts almost $100 \%$ absorption in the spectral range from 200 to $310 \mathrm{~nm}$, some additionally coated quartz sheets $(3.5 \mathrm{~cm} \times 1.5 \mathrm{~cm} \times 1 \mathrm{~mm})$ have also been analysed to determine the spectral transmittance of the films in the respective range. A typical spectrum obtained in this manner is shown in Fig. 6 and discussed in Sect 3.3.

For a comprehensive study of the influence of deposition parameters on the light absorption properties of the films, the spectral absorptance

$$
A_{\lambda}=1-T_{\mathrm{F}}(\lambda)
$$

has been determined for the characteristic spectral positions at $\lambda=310,325,400$ and $500 \mathrm{~nm}$.

In (2), the spectral transmittance of films

$$
T_{\mathrm{F}}=\frac{T_{\text {Film } / \text { Substrate }}}{T_{\text {Substrate }}}
$$

is derived by means of the spectral transmittance of the uncoated substrate $T_{\text {Substrate }}$ and the spectral transmittance of the respective substrate coated, $T_{\text {Film/Substrate }}$.

According to Beer-Lambert's law, a spectral absorption coefficient

$$
a_{\lambda}=-\frac{1}{d} \ln \left(T_{\mathrm{F}}\right)
$$

has been derived as well. Here, $d$ represents the film thickness. Furthermore, the cut-off wavelength $\lambda_{\mathrm{c}}$ of each film deposited has been determined, defining the spectral position, where transmission is reduced to $30 \%$, what corresponds to $-3 \mathrm{~dB}$ of total absorption. 


\section{Results}

\subsection{Chemical composition of the films}

While keeping the temperature of TTIP constant at $353 \pm 1 \mathrm{~K}$, the oxygen flow rate $Q_{\text {tot }}$ was varied such as to vary the oxygen-to-TTIP ratio $q$ in the range from 58 to 12 . With regard to the chemical composition of the films deposited on PET, Si wafer samples coated under the same conditions were examined by XPS, which is a preferable method to analyse thin films since it has an information depth of some nanometers. However, the ex situ analysis of the chemical state of elements in titanium oxide-like films is difficult, because the necessary argon ion sputtering, applied to obtain a clean spot of analysis, has been found to alter the chemical structure of the material under investigation. The same effect has already been addressed by McCurdy et al., who showed that due to preferential sputtering of oxygen by the ion bombardment at energies of $2 \mathrm{kV}$ (initially existing) $\mathrm{TiO}_{2}$ becomes reduced, forming the sub-oxides $\mathrm{Ti}_{2} \mathrm{O}_{3}$ and $\mathrm{TiO}$ [33].

Since in opposition to McCurdy et al. films, in this study, underwent sputtering at $4 \mathrm{kV}$ prior to analysis, a reference of $\mathrm{TiO}_{2}$ (approximately $100 \mathrm{~nm}$ thick) was sputtered (15-45 s) and analysed under the same conditions in order to identify the impact of the preceding sputtering on the results of analysis. The reference has been prepared by thermal oxidation ( $773 \mathrm{~K}$, for $1 \mathrm{~h}$, in air) of a titanium sheet (ADVENT LTD.) with a purity of more than $99.6 \%$.

The spectra obtained reveal that oxygen, titanium and carbon are the major constituents of the films deposited, while carbon is negligible at the reference. In some films, nitrogen, chromium and silicon were sporadically observed, however, with atomic concentrations smaller than $0.2 \%$.

On the basis of the $\mathrm{O} 1 \mathrm{~s}$, Ti2p and the $\mathrm{C} 1 \mathrm{~s}$ photo-electron peaks, the elemental concentrations were determined. In Table 1, the elemental composition of the $\mathrm{TiO}_{2}$ reference is shown, after being sputtered for $45 \mathrm{~s}$. In comparison to the value of $[\mathrm{O}] /[\mathrm{Ti}]=2.03$ for $15 \mathrm{~s}$ of sputtering, the ratio of $[\mathrm{O}] /[\mathrm{Ti}]=1.75$ is diminished after sputtering for $45 \mathrm{~s}$. Thus, a portion of the initially existing pure $\mathrm{TiO}_{2}$ has apparently experienced chemical reduction.

Depth profiling of a film deposited (at $c_{\text {TTIP }}=2.6 \%$ ) revealed a similar effect, causing a change of the elemental composition up to 2 min of sputtering before remaining constant. At this stationary state, a ratio of $[\mathrm{O}] /[\mathrm{Ti}] \approx 1.35$ and a carbon content of approximately $4 \%$ are reached.

In Table 1, the concentrations of the major elements of the films sputtered for $30 \mathrm{~s}$ are listed versus the concentration of TTIP during the plasma deposition process. Despite a quadruplicating concentration of TTIP from $1.7 \%$ to $7.4 \%$, the resulting elemental composition remains virtually unchanged. In comparison to the stoichiometry of TTIP, the carbon content is drastically reduced from nearly $74 \%$ to $8 \%$ at maximum. As a result, the concentrations of oxygen and titanium have increased. At all films, the ratios of $[\mathrm{O}] /[\mathrm{Ti}] \approx 1.7$ were found

Table 1 Elemental composition (atomic-\%) of films deposited at different precursor concentrations and sputtered for $30 \mathrm{~s}$

* Reference sample thermally oxidised and sputtered for $45 \mathrm{~s}$ before analysis

\begin{tabular}{lllllll}
\hline$c_{\text {TTIP }}[\%]$ & 1.7 & 1.9 & 2.6 & 3.8 & 7.4 & $\mathrm{TiO}_{2}^{*}$ \\
\hline $\mathrm{O}_{2} / \mathrm{TTIP}$ ratio $q[-]$ & 57.8 & 51.6 & 37.5 & 25.3 & 12.5 & - \\
$\mathrm{C}(1 \mathrm{~s})[\%]$ & 6.7 & 7.0 & 6.7 & 7.9 & 8 & 0.3 \\
$\mathrm{O}(1 \mathrm{~s})[\%]$ & 58.8 & 58.5 & 59.7 & 58.5 & 57.9 & 63.4 \\
$\mathrm{Ti}(2 \mathrm{p})[\%]$ & 34.5 & 34.5 & 33.6 & 33.7 & 34.1 & 36.3 \\
{$[\mathrm{O}] /[\mathrm{Ti}]$} & 1.70 & 1.70 & 1.78 & 1.74 & 1.70 & 1.75 \\
\hline
\end{tabular}


to correspond with respective value of the chemically reduced $\mathrm{TiO}_{2}$ reference due to the sputtering prior to analysis.

Furthermore, at both type of samples $\left(\mathrm{TiO}_{2}\right.$ reference and deposited films) sputtered, the peaks of the $\operatorname{Ti}(2 \mathrm{p})_{1 / 2}$ and $\operatorname{Ti}(2 \mathrm{p})_{3 / 2}$ core levels are similarly broad and overlapping each other, revealing a similar composition of the oxides of titanium: $\mathrm{Ti}_{2} \mathrm{O}_{3}, \mathrm{TiO}_{2}$ and $\mathrm{TiO}$ (Fig. 3a). Since a similar finding has been described by McCurdy et al. [33] for pure $\mathrm{TiO}_{2}$ after sputtering, it is likely that the majority of the titanium detected, in the films, is originally present as $\mathrm{TiO}_{2}$, as in the case of the reference sample.

The C(1 s) spectrum (Fig. 3c), nevertheless, features the chemical formations Ti-C, C-C, respectively, $\mathrm{C}-\mathrm{H}$ and $\mathrm{C}-\mathrm{O}$ at binding energies of $282.2 \mathrm{eV}$ [45], 285.0 eV and $286.2 \mathrm{eV}$ [46], suggesting a small quantity of titanium-organic and pure organic structures present in the films. On the other hand, the $\mathrm{O}(1 \mathrm{~s})$ spectrum accounts for the presence of $\mathrm{Ti}-\mathrm{O}$-Ti structures only (Fig. 3b). According to McCurdy et al. [33], the shoulder of the $\mathrm{O}(1 \mathrm{~s})$ peak at $535.3 \mathrm{eV}$ results from a charge transfer due to the reduction of $\mathrm{TiO}_{2}$ by the sputtering [33]. This is especially true since the entire carbon amount of the films is small. Although the presence of $\mathrm{Ti}-\mathrm{O}-\mathrm{C}$ could result in a similar shoulder of the $\mathrm{O}(1 \mathrm{~s})$ peak at $535.3 \mathrm{eV}$, the portion of $\mathrm{C}-\mathrm{O}$ bonds (Fig. 3c) attributable to $\mathrm{Ti}-\mathrm{O}-\mathrm{C}$ is too small to account for a shoulder as significant as it is present in the $\mathrm{O}(1 \mathrm{~s})$ spectrum (Fig. 3b).

Furthermore, the organic fraction of the films was detected to increases slightly $(4 \%<[\mathrm{C}]$ $<8 \%$ ) with increasing concentration of TTIP. It reveals the presence of a small portion of Ti-C containing structures (Fig. 3c), a bond not present in the precursor. Its origin cannot be fully enlightened since it could also be formed due to the reducing effect of the argon ion sputtering applied. In addition, the formation of $\mathrm{Ti}-\mathrm{C}$ is rather unlikely under the influence of the plasma in a highly oxidative atmosphere since only $\mathrm{Ti}-\mathrm{O}$ bonds are present in the precursor, which is its strongest bond.

Thus, re-correcting the detected elemental composition of the sputtered films by considering all the detected titanium to be present in $\mathrm{TiO}_{2}$, as suggested above, would lead to an atomic concentration of the $\mathrm{TiO}_{2}$ fraction of at least $93 \%$ in all films deposited.

\subsection{Film thickness and growth rate}

The thickness of films deposited has been measured by means of ellipsometry. With respect to a sub-study performed on the reproducibility of film thickness obtained at the concentration of $c_{\text {TTIP }}=2 \%$, the thickness was found to vary by $\pm 6.2 \mathrm{~nm}$ corresponding to a relative error of approximately $4 \%$. However, the film thickness and thus growth rate appear to vary more drastically at higher precursor concentrations.

This is illustrated by Fig. 4. Here, the resulting dependencies of the growth rate on $c_{\text {TTIP }}$ are compared for the deposition times of $t_{\mathrm{D}}=5$ and $10 \mathrm{~min}$, which show the growth rate to deviate at $c_{\text {TTIP }}=6.3 \%$. Nevertheless, the value obtained is still within the double of the relative error derived for $c_{\text {TTIP }}=2 \%$. Entire surface cleaning of the vacuum chamber and annular gas shower done in between the experiments seems to be responsible for the change observed.

However, excluding the differing values for $c_{\text {TTIP }}=6.3 \%$, the growth rate was generally found to increase with $c_{\text {TTIP }}$. Accordingly, the growth rate increases linearly from $32 \mathrm{~nm} / \mathrm{min}$ at $c_{\text {TTIP }}=2 \%$ to $48 \mathrm{~nm} / \mathrm{min}$ for $c_{\text {TTIP }}=8 \%$ in case of $5 \mathrm{~min}$ deposition time. For $10 \mathrm{~min}$ deposition time, a similar dependence is obtained for concentrations of TTIP below 4\%. At doubled concentration, however, the rate is significantly smaller than in the case of 5 min deposition time. 

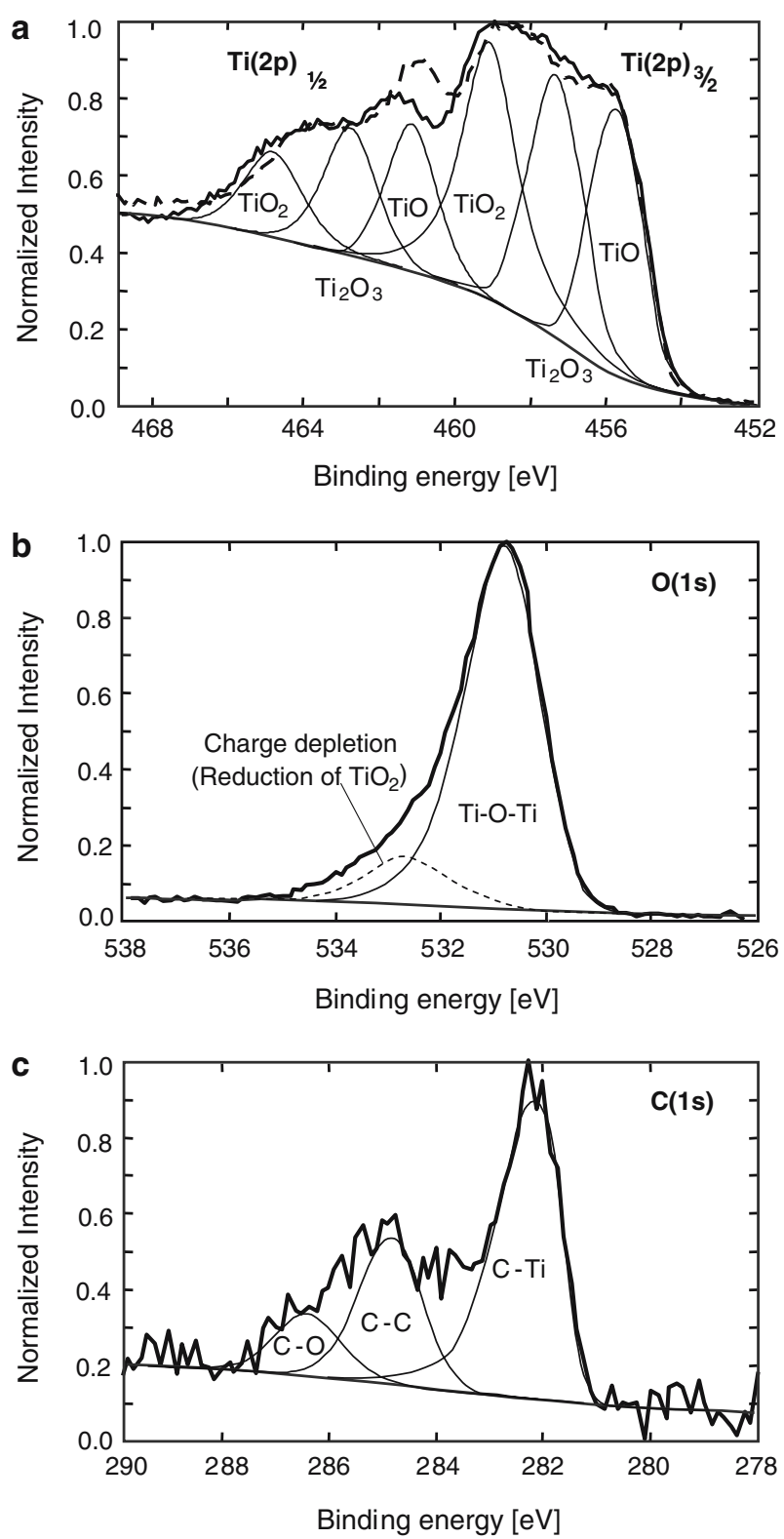

Fig. 3 (a) Spectra of the $\mathrm{Ti}(2 \mathrm{p})_{1 / 2}$ and $\mathrm{Ti}(2 \mathrm{p})_{3 / 2}$ peaks obtained at films (solid line), and spectrum of the $\mathrm{Ti}(2 \mathrm{p})_{1 / 2}$ and $\mathrm{Ti}(2 \mathrm{p})_{3 / 2}$ peaks obtained at the reference sample of pure $\mathrm{TiO}_{2}$ (dashed line). Prior to analysis, samples of films deposited were cleaned by $4 \mathrm{kV} \mathrm{Ar}{ }^{+}$bombardment for $30 \mathrm{~s}$ and the reference for $45 \mathrm{~s}$. The indicated peak attribution of chemical structures has been done according to literature [33, 45, 46]. (b) Spectrum of the $\mathrm{O}(1 \mathrm{~s})$ peak obtained at films deposited. Prior to analysis, samples were cleaned by $4 \mathrm{kV}$ $\mathrm{Ar}^{+}$bombardment for $30 \mathrm{~s}$. The indicated peak attribution of chemical structures has been done according to literature $[33,45,46]$. (c) Spectrum of the C(1 s) peak obtained at films deposited. Prior to analysis, samples were cleaned by $4 \mathrm{kV} \mathrm{Ar}{ }^{+}$bombardment for $30 \mathrm{~s}$. The indicated peak attribution of chemical structures has been done according to literature [33, 45, 46] 


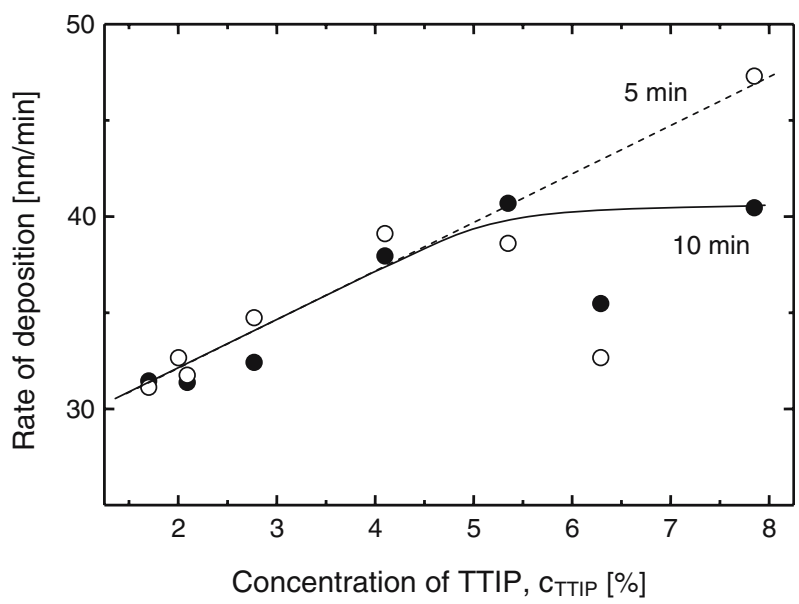

Fig. 4 Dependence of the film growth rate on precursor concentration at different deposition times: $t_{\mathrm{D}}=5$ and $10 \mathrm{~min}$ in $\mathrm{O}_{2} /$ TTIP gas mixture. Rate derived from ellipsometric measurements of the film thickness and the deposition time

This finding can be explained by the observed increase of powder formation with increasing precursor concentration in the gas phase. It is obvious that the process of gas-phase nucleation reduces the flux of species contributing to the deposition on the substrate. Since the number of powder particles formed will increase with progressing time, the observed reduction of the film growth rate for longer deposition times is inevitable.

Profiling of the film surface underlines the increasing role of gas-phase nucleation with increasing precursor concentration. Here, a qualitative increase of the film surface roughness could be observed. In Fig. 5, four surface profiles are shown, which have been acquired to estimate the film thickness by means of a step in the deposited layer (Sect 2.3). All profiles

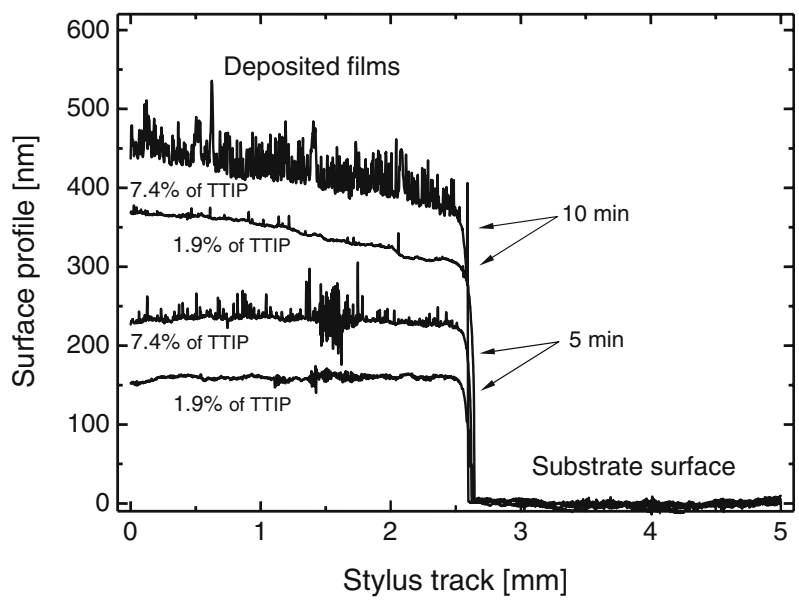

Fig. 5 Surface profiles of four films deposited with steps in the layer in order to measure the film thickness. Films were deposited for $t_{\mathrm{D}}=5$ and $10 \mathrm{~min}$ in $\mathrm{O}_{2} / \mathrm{TTIP}$ gas mixture with precursor concentrations of $c_{\text {TTIP }}=1.9 \%$ and $7.4 \%$, respectively 
feature this step from the top of the film down to the substrate surface at about midway of the total stylus track of $5 \mathrm{~mm}$.

The increase of the surface roughness from $c_{\text {TTIP }}=1.9 \%$ to $7.4 \%$ is evident for both $t_{\mathrm{D}}=5 \mathrm{~min}$ and $10 \mathrm{~min}$. However, the film roughness hardly changes with increasing deposition time at $c_{\mathrm{TTIP}}=1.9 \%$, whereas it increases significantly with prolonged deposition time at $c_{\text {TTIP }}=7.4 \%$. Thus, the increase of roughness with the concentration of TTIP appears to be predominantly governed by larger species from the gas phase being adsorbed.

\subsection{UV and visible light absorbed by deposited films}

The transmittance spectra of a film deposited on PET and on quartz, and the spectral transmittance of an uncoated PET substrate are shown in Fig. 6. Here, the spectrum of the film deposited on PET is only shown for 310 to $500 \mathrm{~nm}$, because the strong absorption effect of PET, below $310 \mathrm{~nm}$, inhibited meaningful analysis of the absorption effect being exerted by the deposited film. Furthermore, the high-frequency oscillation impressed to the spectra of the film deposited on PET and of the uncoated PET is attributed to interference due to multiple internal reflections at the interfaces of the PET film substrate. Interference is also believed to cause the deviation of the spectra of films deposited on quartz from those on PET above $350 \mathrm{~nm}$ [27]. Here, an oscillation with lower frequency is observed, because the quartz substrate is 83 times thicker than the PET film, see Sect 2.4. Interference phenomena are though known to vanish at lower wave lengths. Consequently, since the spectra of films on quartz and PET were found to agree well below $375 \mathrm{~nm}$, spectra of films on quartz can be considered to reflect the spectral behaviour of films deposited on PET, especially in the range below $310 \mathrm{~nm}$.

The film spectrum shown in Fig. 6 is characteristic of all films deposited. In the range from 350 to $500 \mathrm{~nm}$, the transmittance of films is generally higher than that of PET, although $100 \%$ transparency was never obtained. The film transmittance is progressively reducing from $350 \mathrm{~nm}$ towards lower wave lengths. Thus, compared to the spectral transmittance of PET (Fig. 6), an effective absorption of UV radiation is already obtained at higher wave lengths,

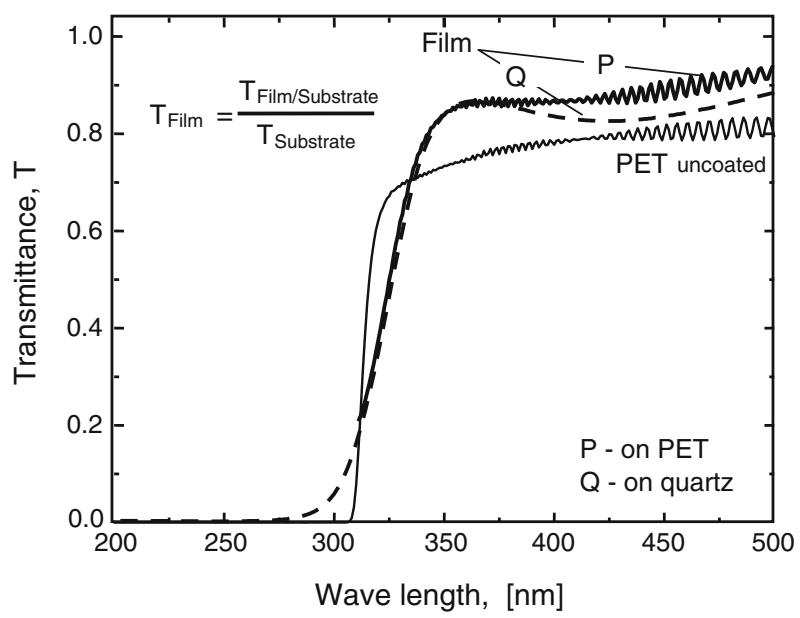

Fig. 6 Transmittance of a film, $T_{\mathrm{F}}$ (see (3)), which has been deposited at $c_{\mathrm{TTIP}}=5.4 \%(5.35 \%$ PETTiO021A; QT004) for $t_{\mathrm{D}}=5 \mathrm{~min}$ in $\mathrm{O}_{2}$ /TTIP mixture on PET and on quartz substrates; additionally compared to the transmittance $T_{\mathrm{PET}}$ of an uncoated PET substrate 
although the spectral transmittance of the film is slightly higher than for PET between 275 and $310 \mathrm{~nm}$. Then, at wavelength lower than $275 \mathrm{~nm}$, films deposited exert almost $100 \%$ absorption.

This finding is in opposition to results obtained by Fitzgibbons et al. [27] at poly-crystalline $\mathrm{TiO}_{2}$ on quartz, whose transmittance increased to approximately $80 \%$ with decreasing wave length from 320 to $242 \mathrm{~nm}$ forming an absorption peak centred at around $320 \mathrm{~nm}$. Fitzgibbons et al. assume this behaviour to originate from an electronic transition, being typical for thin films since for bulk single-crystals of rutile, an absorption etch at $410 \mathrm{~nm}$ occurs.

Anyway, the thickness dependency described by Fitzgibbons et al. [27] is unlikely to account for the films deposited for this work since thicknesses are approximately the same. Since Fitzgibbons et al. [27] observed, furthermore, a similar but much broader absorption peak at thin amorphous films, we assume that the broadening as well as the occurrence of absorption etch, as found here, is caused by a change in the chemical structure of the film material.

With regard to the water-vapour assisted deposition method used by Fitzgibbons et al. [27], such a change was very likely to occur when changing the annealing temperature in order to obtain poly-crystalline and amorphous films. Unfortunately, Fitzgibbons et al. do not at all report on the chemical composition of their films.

The cut-off wavelength of the deposited films (transmission reduced to 30\%) turns out to depend on the concentration of TTIP as well as on the time of deposition $t_{\mathrm{D}}$. The corresponding dependencies obtained are shown in Fig. 7. In case of film deposition for $t_{\mathrm{D}}=10 \mathrm{~min}$, no significant dependence of the cut-off wave length has been found for $1.7 \%<c_{\text {TTIP }}<8 \%$, so that a plateau is observed at $\lambda_{\mathrm{c}}=325 \pm 1.8 \mathrm{~nm}$, while it increases with increasing concentration of TTIP in the range from $0.4 \%$ to $1.7 \%$. It can also be seen from Fig. 7 , that a plateau level of $\lambda_{\mathrm{c}}=316.5 \pm 1.6 \mathrm{~nm}$ was obtained for $t_{\mathrm{D}}=5 \mathrm{~min}$ with $c_{\text {TTIP }}>1.7 \%$.

With regard to this and to the fact that film thickness was found to increase with increased deposition time, the cut-off wavelength seems to be affected by an increase of the film thickness for precursor concentrations lower than $1.7 \%$. However, the reason for the plateau level

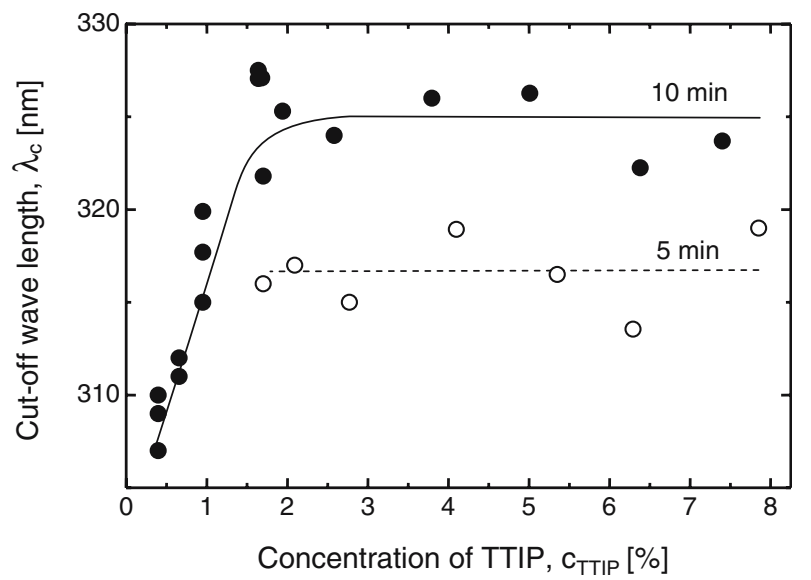

Fig. 7 Dependence of the cut-off wave length of the films deposited on precursor concentration at different deposition times: 5 and $10 \mathrm{~min}$ in $\mathrm{O}_{2}$ /TTIP gas mixture. The lines shown (straight for $10 \mathrm{~min}$ and dashed for $5 \mathrm{~min}$ ) are auxiliary lines to emphasis the tendency of the dependencies obtained 
found above the threshold value $c_{\mathrm{TTIP}}=1.7 \%$, is intended be enlightened by additional results as in the following.

Similar to the cut-off wave length, the spectral absorptance $A_{\lambda}$ and the absorption coefficient $a_{\lambda}$ (Sect 2.4) were found to depend on the deposition parameter. In Fig. 8, the spectral absorptance for $\lambda=310,325,400$ and $500 \mathrm{~nm}$ is plotted against $c_{\text {TTIP. }}$. As observed for the cut-off wave length, the values of $A_{310}$ and $A_{325}$ rise with the increase of $c_{\text {TTIP }}$ up to $1.7 \%$. Since the cut-off wavelength of films deposited has been determined to $\lambda_{\mathrm{c}}=325 \mathrm{~nm}$ for $t_{\mathrm{D}}=10 \mathrm{~min}, A_{325}$ attains cut-off value, while $A_{310}$ increases to $95 \%$. In the same time, $A_{400}$ and $A_{500}$ remain nearly constant at a level of $10 \pm 5 \%$. Above $c_{\text {TTIP }}=1.8 \%$, the spectral absorptance remains constant for all wavelengths monitored. This is also true for the thinner films obtained at $t_{\mathrm{D}}=5 \mathrm{~min}$. Here, the level of film absorptance remains at a lower level with $A_{310}=81 \%$ and $A_{325}=50 \%$.

However, since the film thickness increases with $c_{\text {TTIP }}$ (Sect 3.2), the spectral absorption coefficient $a_{\lambda}$ of films deposited decreases for $c_{\text {TTIP }}>1.7 \%$. Shown in Fig. 9, the coefficient $a_{310}$ drops from $12 \mu \mathrm{m}^{-1}$ (virtually $70 \%$ absorption by a $100 \mathrm{~nm}$ thick film) to $8 \mu \mathrm{m}^{-1}$ due to an increase of $c_{\text {TTIP }}$ from $2 \%$ to $8 \%$. Simultaneously the coefficient $a_{325}$ decreases, while $a_{400}$ and $a_{500}$ appear to increase slightly. Furthermore, the spectral absorption coefficient appears to be the same for films deposited at $t_{\mathrm{D}}=5$ and $10 \mathrm{~min}$.

\section{Discussion}

As derived from XPS analyses in Sect 3.1, films deposited from oxygen-TTIP mixtures on PET resemble the chemical structure of $\mathrm{TiO}_{2}$ with small quantities of carbon containing inclusions; see Fig. 3 and discussion thereon. Their origin could not be fully enlightened, and remains to further investigations.

Since TTIP already provides titanium in chemical liaison to oxygen (at a ratio of 1:4), the chemical composition of the oxide films deposited appears to be invariant against the

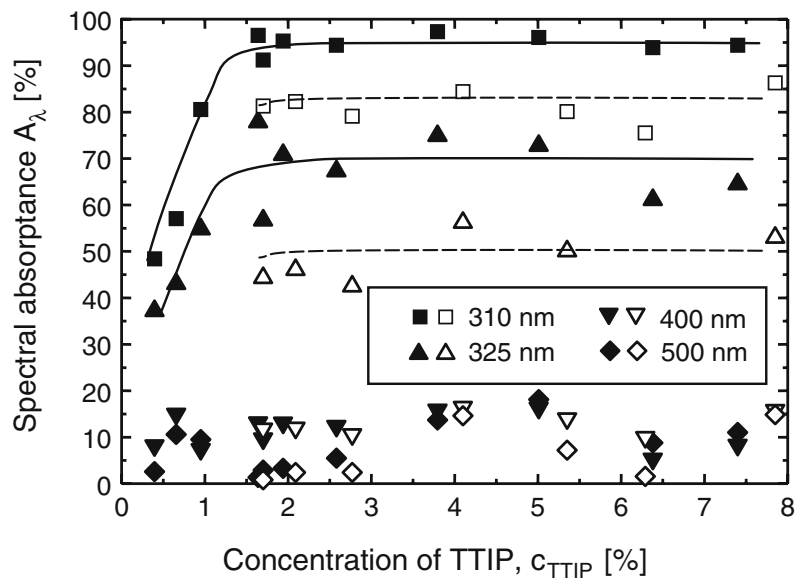

Fig. 8 Dependence of the spectral absorptance on precursor concentration at different characteristic wavelengths. Films deposited for $t_{\mathrm{D}}=5 \mathrm{~min}$ (open symbols) and $10 \mathrm{~min}$ (solid symbols) in $\mathrm{O}_{2} / \mathrm{TTIP}$ mixture. The lines shown (straight for $10 \mathrm{~min}$ and dashed for $5 \mathrm{~min}$ ) are auxiliary lines to emphasis the tendency of the dependencies obtained for $A_{310}$ and $A_{325}$ 


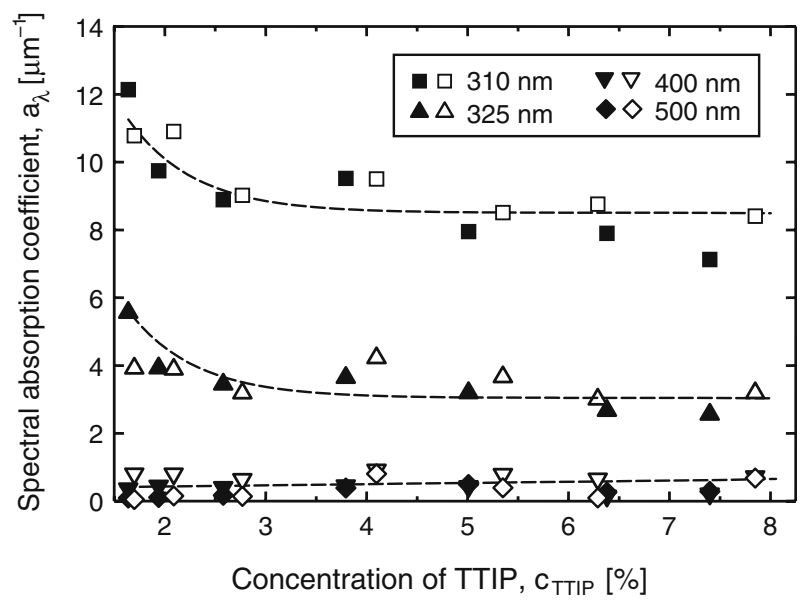

Fig. 9 Spectral absorption coefficients of films versus precursor concentration at different characteristic wavelengths. Films deposited for $t_{\mathrm{D}}=5 \mathrm{~min}$ (open symbols) and $10 \mathrm{~min}$ (solid symbols) in $\mathrm{O}_{2} / \mathrm{TTIP}$ mixture. The dashed lines shown are auxiliary lines to emphasis the tendency of the dependencies obtained

variation of the precursor concentration (1.7-7.4\%), and the variation of the mixing ratio of oxygen to TTIP (58-12), respectively.

As a consequence thereof, the optical cut-off wavelength of the films deposited for $c_{\text {TTIP }}>$ $1.7 \%$ does not significantly depend on the concentration of TTIP (see Fig. 7). Accordingly, films obtained after $10 \mathrm{~min}$ exert cut-off at $325 \mathrm{~nm}$, while cut-off was observed at $316 \mathrm{~nm}$ for the thinner films deposited within $5 \mathrm{~min}$. However, for $c_{\text {TTIP }}<1.7 \%$, the observed effect of the precursor concentration must be attributed to the resultant change of film thickness (Fig. 4), whose influence was clearly elaborated by the comparison of films deposited for $5 \mathrm{~min}$ and for $10 \mathrm{~min}$.

Thus, the observed change of the spectral absorptance of films at small precursor concentrations ( $c_{\text {TTIP }}<1.7 \%$, Fig. 8$)$ is also likely to descent from the resultant change of film thickness. However, above the threshold of $1.7 \%$, the increasing precursor concentration and the resultant increase of film thickness have opposite effects. Hence, depicted in Fig. 9, the spectral absorption coefficient was found to decrease with increasing precursor concentration above the threshold of $c_{\text {TTIP }}=1.7 \%$.

Thus, the absorption effectiveness of the $\mathrm{TiO}_{2}$ films deposited decreases with higher precursor concentrations. Since the films have been found to be chemically invariant (see above), and profilometry (Fig. 5) revealed an increasing surface roughness with increasing precursor concentration, a decrease of the film density causing diminution of the absorption coefficient must be considered.

\section{Conclusions}

Films were deposited from oxygen-TTIP mixtures on PET films by means of PECVD. With respect to chemical properties of the films, it was shown that films of mainly $\mathrm{TiO}_{2}$ are also obtainable in a low-temperature environment on polymeric material.

These films are chemically invariant in a wide range of precursor concentration (1.7$8 \%$ ). With respect to optimal spectral absorptance, the corresponding set of the investigated 
deposition parameters was found to be at approximately $2 \%$ of TTIP and 10 min deposition time, because the absorption coefficient decreases with higher precursor concentrations. This effect is considered to be caused by a decreasing film density. Moreover, lower concentrations of TTIP as well as 5 min deposition time were found to lead to film thicknesses being too small to exert sufficient UV absorption in the range from 230 to $330 \mathrm{~nm}$.

Films deposited at optimal parameters exert cut-off (70\%) at $325 \mathrm{~nm}$ and a spectral absorptance of $95 \%$ at $310 \mathrm{~nm}$, while absorptance in the visible range (at 400 and $500 \mathrm{~nm}$ ) is approximately $10 \%$.

Acknowledgments The authors wish to thank L. Feuz, R. Konradi and Prof. M. Textor (ETH Zurich) for providing the opportunity to conduct ellipsometric measurements and for their support in interpretation. Furthermore, access to the surface profiler used has been offered by U. Lang (ETH Zurich), whose helpfulness is gratefully acknowledged.

\section{References}

1. Campbell SA, Kim HS, Gilmer DC, He B, Ma T, Gladfelter WL (1999) IBM J Res Dev 43(16): 383

2. Balog M, Schieber M, Michman M, Patai S (1972) J Cryst Growth 17(DEC):298

3. Yan J, Gilmer DC, Campbell SA, Gladfelter WL, Schmid PG (1996) J Vac Sci Technol B14:1706

4. Fuyuki T, Matsunami H (1986) J Appl Phys 25:1288

5. Richards BS, Cotter JE, Honsberg CB (2002) Appl Phys Lett 80:1123

6. Szabo G, Kovacs L, Vargha K, Barabas J, Nemeth Z (1999) J Long Term Eff Med Implants 3:247

7. Kurtz SR, Gordon RG (1987) Thin Solid Films 147:167

8. Yeung KS, Lam YW (1983) Thin Solid Films 109(2):169

9. Glocker DE, Ismat Shah S (eds) (1995) Handbook of thin film process technology, vol 2. IOP Publishing, pp X1.3.5:1

10. Pulker HK (1984) Coatings on glass, vol 6. Elsevier, Amsterdam, p 484

11. O'Regan B, Grätzel M (1991) Nature 353:737

12. Kang MG, Park NG, Chang SH, Choi SH, Kim KJ (2002) Bull Kor Chem Soc 23(1):140

13. Fujishima A, Honda K (1972) Nature 238(5358):37

14. Hardee KL, Bard AJ (1975) J Electrochem Soc 122(6):739

15. Jaeger CD, Bard AJ (1979) J Phys Chem 83(24):3146

16. Gamble L, Jung LS, Campbell CT (1996) Sur Sci 348(1-2):1

17. Ichikawa S, Doi R (1996) Catal Today 27(1-2):271

18. Larson SA, Widegren JA, Falconer JL (1995) J Catal 157(2):611

19. Watanabe T, Nakajima A, Wang R, Minabe M, Koizumi S, Fujishima A, Hashimoto K (1999) Thin Solid Films 351(1-2):260

20. Miyauchi M, Kieda N, Hishita S, Mitsuhashi T, Nakajima A, Watanabe T, Hashimoto K (2002) Surf Sci 511(1-3):401

21. Wang R, Hashimoto K, Fujishima A, Chikuni M, Kojima E, Kitamura A, Shimohigoshi M, Watanabe T (1997) Nature 388(6641):431

22. Wang R, Sakai N, Fujishima A, Watanabe T, Hashimoto K (1999) J Phys Chem B103(12):2188

23. Kamei M, Mitsuhashi T (2000) Surf Sci 463:L609

24. Rausch N, Burte EP (1993) J Electrochem Soc 140(1):145

25. Tang H, Prasad K, Sanjines R, Schmid PE, Levy F (1994) J Appl Phys 75(4):2042

26. Chang HLM, You H, Guo J, Lam DJ (1991) Appl Surf Sci 48-9:12

27. Fitzgibbons ET, Sladek KJ, Hartwig WH (1972) J Electrochem Soc 119(6):735

28. Martinet C, Paillard V, Gagnaire A, Joseph J (1997) J Non-Crystalline Solids 216:77

29. Song Y, Sakurai T, Kishimoto K, Maruta K, Matsumoto S, Kikuchi K (1998) Vacuum 51(4):525

30. Battiston GA, Gerbasi R, Gregori A, Porchia M, Cattarin S, Rizzi GA (2000) Thin Solid Films 371(12): 126

31. da Cruz NC, Rangel EC, Wang JJ, Trasferetti BC, Davanzo CU, Castro SGC, de Moraes MAB (2000) Surf Coatings Technol 126(2-3):123

32. Nakamura M, Aoki T, Hatanaka Y, Korzec D, Engemann J (2001) J Mater Res 16(2):621

33. McCurdy PR, Sturgess LJ, Kohli S, Fisher ER (2004) Appl Surf Sci 233(1-4):69

34. Nakamura M, Kato S, Aoki T, Sirghi L, Hatanaka Y (2001) Thin Solid Films 401(1-2):138

35. Nakamura M, Kato S, Aoki T, Sirghi L, Hatanaka Y (2001) J Appl Phys 90(7):3391 
36. Xiang JH, Masuda Y, Koumoto K (2004) Adv Mater 16(16):1461

37. Hatanaka Y, Naito H, Itou S, Kando M (2005) Appl Surf Sci 244(1-4):554

38. Taga Y (1997) J Non-Crystalline Solids 218:335

39. Torikai A, Mitsuoka T, Fueki K (1993) J Polym Sci A 31:2785

40. Rivaton A (1995) Polym Degrad Stab 49:163

41. Mitsuoka T, Torikai A, Fueki K (1993) J Appl Polym Sci 47(6):1027

42. Lahouidak J (1991) Etude de couches minces de $\mathrm{TiO}_{2}$ déposées par CVD et CVD assistée plasma, $\mathrm{PhD}$ Thesis at University of Montpellier, Ecole nationale supérieure de chemie de Montpellier, P 51

43. Smith RC, Ma TZ, Hoilien N, Tsung LY, Bevan MJ, Colombo L, Roberts J, Campbell SA, Gladfelter WL (2000) Adv Mater Opt Electron 10(3-5):105

44. Goossens A, Maloney EL, Schoonman J (1998) Chem Vapor Depos 4(3):109

45. Zehnder T, Patscheider J (2000) Surf Coatings Technol 133:138

46. Sonnenfeld A, Tun TM, Zajicková L, Kozlov KV, Wagner H-E, Behnke JF, Hippler R (2001) Plasmas Polym 6(4):237 